\title{
A FENOMENOLOGIA DA EXPERIÊNCIA JURÍDICA EM ADOLF REINACH
}

\author{
Carlos Morujão
}

Universidade Católica Portuguesa

O objetivo deste ensaio é fazer uma apresentação da obra de Adolf Reinach Die apriorischen Grundlagen des bürgerlichen Rechts (Os Fundamentos a priori do Direito Civil), publicada em 1913 no $10^{\circ}$ volume dos Jahrbücher für Phänomenologie und phänomenologische Forschung, a cujo comité redatorial o próprio Reinach pertencia. Penso que esta obra só será totalmente inteligível a partir de uma compreensão da doutrina husserliana dos atos intencionais, exposta nas Investigações Lógicas, em particular na 5. Investigação, mas, também, a partir de algumas pequenas, mas significativas, alterações que Reinach nela introduziu. Será isto que tentarei demonstrar à medida que for expondo algumas das ideias fundamentais dos Grundlage.

Começarei por mencionar uma das teses principais de Husserl sobre a natureza dos atos intencionais, que é a de que eles podem estar dirigidos para uma objetividade, no sentido lato do termo, independentemente de se saber se ela é real ou ideal, possível ou impossível, etc. Dever-se-á entender por objetividade todo o correlato de um ato, podendo ela, enquanto tal, não existir sob a forma particular de objeto atualmente dado e transcendente a esse ato. Como exemplos de um correlato sem esta última forma particular poderíamos mencionar os habitantes de Marte, o deus Júpiter, ou um círculo quadrado. Que um objeto seja visado, afirma-se no $\S 11$ da 5. Investigação Lógica, significa apenas que certas vivências estão presentes, seja com intenção representativa, judicativa, optativa, ou outra. ${ }^{1} \mathrm{Na}$ mesma ordem de ideias, afirmava-se, no $\S 14$ da $1 .^{\text {a }}$ Investigação, ${ }^{2}$ que o conteúdo de um ato pode ser

${ }_{1}$ Husserl, Logische Untersuchungen (de agora em diante: LU) V, § 11, Hua XIX/1, 385-386.

2 Husserl, LU I, § 14, Hua XIX/1, 56. 
entendido em três acepções diferentes; na de sentido visado, na de preenchimento do sentido visado, e, por fim, na acepção de objeto; por este motivo, na unidade de recobrimento (Deckungseinheit) entre a primeira e a segunda acepções, que possibilita o preenchimento do sentido visado, o objeto pode não estar presente e não ser percepcionado. Falar-se de uma unidade de recobrimento significa apenas que estamos diante de uma significação idêntica, que se pode captar corretamente sem que, para tal, haja necessidade de uma perceção. Ora, a possibilidade de o objeto não estar presente, ou seja, a ausência do que constitui, para Husserl, a terceira aceção do conteúdo de um ato, é privilegiada por Reinach: não no sentido de Reinach dizer que é mais frequente a ausência do que a presença do objeto, pois, na realidade, nunca se refere à questão nestes termos, mas sim no sentido de levar a cabo as suas análises como se esta terceira dimensão não fosse pertinente. É o que transparece da sua teoria dos estados de coisas. O estado de coisas (Sachverhalt) produzido por uma frase não tem de ser uma objetividade efetivamente existente, sem que, ao ser esse o caso, tal implique que tenhamos de o fazer corresponder ao conteúdo psíquico da representação. Toda a sua teoria da natureza das configurações jurídicas se apoia nesta concepção particular do que sejam os estados de coisas. Há, em Reinach, uma crítica do representacionismo, desenvolvida, antes ainda dos Grundlage, em 1911, num ensaio intitulado «Teoria do Juízo Negativo», ao qual voltarei um pouco mais adiante. De acordo com Reinach, os estados de coisas (Sachverhalte), expressos nos juízos, são uma espécie de entidades às quais apenas em alguns casos deveremos fazer corresponder objetos individuais e acontecimentos do mundo real. Os estados de coisas seriam assim, apenas, os correlatos intencionais de um certo tipo de atos, não sendo necessário atribuir-lhes qualquer existência autónoma relativamente a eles. O que Reinach quer dizer é que juízos como, por exemplo, «esta rosa é vermelha», não seriam substancialmente diferentes de juízos do género «esta rosa não é azul», embora, neste último caso, a propriedade expressa pelo predicado não tenha uma existência autónoma, mas seja apenas pensada ou visada. Este último estado de coisas, por conseguinte, não teria de ser distinguido do primeiro, mesmo não possuindo a mesma existência autónoma daquele. ${ }^{3}$ Se interpreto corretamente as ideias de Reinach, encontraremos aqui um primeiro afastamento relativamente a Husserl, embora de certa forma legitimado, no texto das Investigações Lógicas, pelo modo como o próprio Husserl define

${ }^{3} C f$., em sentido contrário, a opinião de Roman Ingarden, em Der Streit um die Existent der Welt, Band II/1, § 53. Tübingen: Max Niemeyer, 1965, pp. 292 e ss., esp. pp. 306-307. Dissemos acima que Reinach efectua as suas análises como se a terceira acepção de conteúdo de um ato não fosse pertinente; todavia, na sua crítica a Reinach, Ingarden (ob. cit., pp. 300-301) regista duas passagens da «Teoria do Juízo Negativo» em que tal não acontece. 
a terceira aceção de conteúdo de um ato. Se um estado de coisas negativo subsiste, independentemente de uma operação judicativa que negue que um certo predicado «p» pertença a um sujeito «S» - por exemplo, que o predicado «azul» pertença ao sujeito «rosa» -, então será possível admitir que as «configurações jurídicas», de que falarei na próxima seção, e as vinculações que resultam da sua existência, igualmente subsistam independentemente do seu reconhecimento pelo direito positivo, ou das normas que este prescreve para a sua regulamentação.

\section{As configurações jurídicas}

As «configurações jurídicas», ${ }^{4}$ como, por exemplo, as reivindicações, as pretensões, as obrigações, a propriedade, etc., não são, por conseguinte, atos psicológicos, possuindo, diz Reinach, o mesmo tipo de existência que as casas, as árvores e os números: ${ }^{5}$ ou seja, o seu ser é independente do nosso reconhecimento. Todavia, ao invés das casas e das árvores, tais configurações não podem ser captadas no mundo exterior com atos de perceção sensível, pois não são objetos singulares com predicados cambiantes, como as casas que podem ser brancas, ou as árvores que podem estar em flor. ${ }^{6}$ São entidades dotadas de uma temporalidade específica - diferente da dos atos em que se constituíram, mas também da omnitemporalidade das idealidades lógicas e matemáticas -, independentes de quem as concebe (são transcendentes, no sentido fenomenológico do termo), formadas por relações de essência semelhantes às que encontramos nos números ou nas figuras geométricas. Só na medida em que devem ser consignadas pelo direito positivo (o qual, no entanto, as encontra por assim dizer já feitas, não as cria, assim como a ciência histórica não cria os factos históricos ${ }^{7}$ ), só nesta medida - dizia - é que elas podem depender, por exemplo, das representações morais de uma época, ou das suas necessidades económicas. No $\S 1$ da Introdução aos Grundlage, apresenta-se o exemplo da relação entre um credor e um devedor em que, segundo as normas jurídicas vigentes - Reinach refere-se ao Código Civil Alemão, nos princípios do século XX -, as dívidas podem ser transferidas a terceiros pelo credor sem a anuência do devedor. ${ }^{8}$ Trata-se de uma proposição do direito positivo ger-

4 Traduzirei deste modo, de agora em diante, a expressão alemã rechtliche Gebilde.

5 Reinach, Die apriorischen Grundlagen des bürgerlischen Rechts, $\S 1$, in Sämtliche Werke (de agora em diante: SW), Band 1. München: Philosophia Verlag, 1989, p. 143.

$6 \mathrm{SW}, 143-144$.

$7 \mathrm{SW}, 143$.

$8 \mathrm{SW}, 141$. 
mânico da época, mas que poderá perder o seu valor em épocas diferentes. Tal proposição não possui verdade ou falsidade intrínsecas e foram necessidades económicas específicas que conduziram à sua instituição. Isto não quer dizer, contudo, que disposições desta natureza sejam a aplicação consciente, a uma situação histórica determinada, de leis essenciais. Estas leis, dirá Reinach, produzem os seus efeitos à maneira das leis da lógica, que conduzem os pensamentos dos homens sem entrarem na sua consciência e sem necessidade de serem formuladas. ${ }^{9}$

É, assim, a partir de uma análise da promessa que, do $§ 2$ dos Grundlage em diante, Reinach vai tentar clarificar esta problemática, inspirando-se, manifestamente, para explicitar o que entende por «leis essenciais», na noção de a priori material, que Husserl desenvolvera, em 1901, nas Investigações Lógicas. A aplicação desta noção fenomenológica a uma explicação da natureza da promessa implicará, para Reinach, admitir que a relação entre quem contrai uma obrigação e aquele perante quem ela foi contraída possa ser da mesma índole que a relação entre, por exemplo, uma cor e uma superfície, para utilizar um dos exemplos mais conhecidos de Husserl na 3. Investigação Lógica. ${ }^{10}$ É exatamente este mesmo tipo de vínculo essencial que Reinach, no $\S 5$ dos Grundlage, afirma também existir na relação de propriedade, a qual estabelece que o possuidor de uma coisa tem o direito absoluto de se comportar perante ela do modo que entender. ( $O$ facto de haver outro tipo de obrigações jurídicas, ou mesmo deveres de carácter moral, que impedem o proprietário de exercer o seu direito, nada tem a ver com a essência da relação assim estabelecida, da qual decorrem direitos absolutos. ${ }^{11}$ ) Ora, apesar de todas estas relações possuírem um carácter temporal específico que as distinguem dos objetos espaciais - e não será demais insistir na semelhança que, sob este aspeto, os Grundlage estabelecem entre elas e as entidades lógicas e matemáticas -, Reinach menciona o problema da sua criação ou destruição, o que, obviamente, as distingue destas últimas entidades. Julgo que convém ter em atenção o seguinte: a criação e a destruição referem-se apenas aos produtos dos atos sociais que estabelecem relações do género da promessa e lhes conferem a forma de uma lei positiva, não aos princípios a priori que regulam a produção desses atos. ${ }^{12}$ Assim, se a pretensão a ver uma promessa

$9 \mathrm{SW}, 262$.

${ }^{10} C f$. Ronan de Calan, «Introduction» à trad. franc. de Adolf Reinach, Les Fondements A Priori du Droit Civile. Paris: Vrin, 2004, p. 10.

$11 \mathrm{SW}, 194$.

12 Stanley L. Paulson, «Demystifying Reinach's legal theory». In: Kevin Mulligan (Ed.), Speech Act and Sachverhalt, Dordrecht / Boston / Lancaster: Martinus Nijhoff, 1996, pp. 133-154, pp. 145-146. 
realizada cessa naturalmente quando quem prometeu cumpriu a promessa, ela já não cessa quando a vivência da promessa, seja por quem prometeu, seja por quem foi o seu destinatário, não é uma vivência atual. (Por exemplo, durante o sono. ${ }^{13}$ )

Promessas ou ordens exprimem-se em frases não-declarativas, ou seja, elas não são frases «constativas» no sentido que John Austin, na sua teoria dos Speechacts, atribuía a este termo: elas não dizem o que acontece, embora, como veremos, elas façam com que aconteça. A doutrina dos estados-decoisas de Reinach, desenvolvida, como disse anteriormente, no ensaio «Teoria do Juízo Negativo», parece ter por objetivo libertar o mero visar de qualquer relação com a representação, quebrando assim o privilégio concedido por Husserl aos atos objetivantes, ou seja, a todas aquelas vivências intencionais que, dado o seu carácter representacional, servem um interesse de conhecimento. É assim que, com uma promessa ou com uma ordem, há qualquer coisa que é visada, mas não é ainda representado um estado de coisas, sem que isto signifique que tais atos possuam alguma «deficiência» por comparação com os atos objetivantes. Situo aqui o segundo afastamento de Reinach em relação a Husserl.

Este ponto merece que me detenha nele mais um pouco, pois acontece que Husserl, no $\S 68$ da 6 . $^{\mathrm{a}}$ Investigação Lógica, levanta, embora para a refutar de seguida, a hipótese, ao que parece formulada pela primeira vez por Sigwart, mas já talvez por Bolzano também, de mesmo as frases não assertivas (por exemplo, optativas, desiderativas, ou outras) conterem uma asserção. Assim, por exemplo, quem exprime um desejo, ao mesmo tempo, implicitamente, assevera que deseja; se quanto ao desejo em si mesmo não fará sentido perguntar pela verdade ou falsidade, faz sentido perguntar-se pela veracidade da sua expressão; ou seja, como é sempre possível a alguém escolher, para o exprimir, palavras que não convêm, ou ter um discurso deliberadamente dececionador, diremos, neste caso, que não está a falar verdade. Ora, parece-me que Reinach encara de forma diferente de Husserl a natureza das frases não assertivas, sem admitir aquela solução de Sigwart. O ponto central parece-me a mim residir no seguinte: quem promete faz mais do que manifestar a intenção de prometer, tal como quem ordena faz mais do que manifestar a intenção de ordenar. O que interessa a Reinach não é apenas constatar a ausência de um estado de coisas objetivo anterior aos atos não objetivantes, que é o terreno em que se situam as análises de Husserl; quanto a este ponto, não parece haver discordância entre os dois autores. O interesse de Reinach consiste, pelo contrário, em saber que novo estado de coisas é criado por certo tipo de atos como aqueles a que chamamos promessa ou ordem. 
O raciocínio de Reinach pode reconstituir-se da seguinte maneira. ${ }^{14}$ Quando pensamos numa promessa (o indivíduo A promete qualquer coisa ao indivíduo $B$ ), pensamos que entre o facto de alguém prometer e a expetativa de se ver a promessa cumprida se estabelece uma relação que não é acidental, mas sim de essência. Uma promessa não seria tal se um determinado tipo de relação entre dois indivíduos A e B não viesse a ser estabelecido: ou seja, se não se produzisse um efeito específico distinto, por exemplo, de uma ordem ou de uma pergunta. Essa relação de essência supõe, pelo menos, três condições: 1) que num determinado momento do tempo alguém tenha iniciado uma frase por «eu prometo que...»; 2) que existe uma cessação da promessa quando quem prometeu cumpre o que prometeu; 3) que existe igualmente cessação quando aquele a quem foi prometido renuncia à promessa. Mas, como diz Reinach: «Quando uma promessa é enunciada - e eu acrescentaria: pelo simples facto de ter sido enunciada -, qualquer coisa de novo surge no mundo»...$^{15}$

Para Husserl, uma vivência intencional não se limita a visar, mas, nos casos normais, além de estar na expetativa de um preenchimento da visada, está também na expetativa de que um objeto, ou um estado de coisas, lhe corresponda. Por isso é que Husserl afirmava, na 1. Investigação Lógica, que o objeto pertence também ao conteúdo do ato. Provavelmente haverá aqui alguma dependência relativamente a Brentano e à sua noção de representação e, em particular, à tese deste último segundo a qual todos os atos não representativos (desiderativos, volitivos, etc.) se fundam numa representação prévia. ${ }^{16}$ Ora este suposto «caso normal» não é tal para Reinach, que retém da tese de Husserl, simplesmente, que o juízo visa um estado de coisas objetivo, que é independente da consciência judicativa e do ato psíquico de julgar. É aqui que situo o terceiro afastamento de Reinach em relação a Husserl: os estados de coisas são pensáveis antes de serem representáveis, ou seja, antes de existirem. Não posso pensar uma cor sem uma extensão, como vimos; assim, não posso também pensar uma promessa ou uma ordem sem a vinculação (Verbindlichkeit) que elas estabelecem.

Aqui, há que registar o carácter pouco exato, em meu entender, da leitura da 5. Investigação Lógica feita pelo tradutor francês dos Grundlagen. Referindo-se à génese da teoria dos «estados de coisas» em Reinach, Ronan de Calan, na "Introdução» à sua tradução, ${ }^{17}$ começa por dizer que tal teoria prolonga um modelo de análise intencional, inaugurado por Husserl, que neu-

14 SW, 148-149.

15 Como veremos mais adiante, é na base desta tese que Reinach criticará a teoria da promessa em David Hume.

16 Ronan de Calan, art. cit., p. 28.

${ }^{17}$ Ibid., pp. 26-27. 
traliza a questão da existência efetiva do objeto. Uma referência é feita ao $\S 11$ da $5 .{ }^{\text {a }}$ Investigação, ${ }^{18}$ ao qual me referi já, onde Husserl simplesmente diz que a peculiaridade das vivências intencionais é referirem-se, de vários modos, a objetos representados. Tal não me parece significar uma «neutralização» do objeto, mas sim, ao invés, afirmar que quando certas vivências estão presentes um objeto é visado por elas, devendo a palavra «objeto» ser entendida no sentido lato: uma mesa, um conceito matemático, ou o deus Júpiter são objetos de pleno direito. Mas o mais contestável na tese de Calan, o que me parece introduzir uma distorção no pensamento de Husserl graças ao recurso a uma citação truncada, é o referido tradutor dizer que Husserl inaugura um modelo de referência objetiva sem objeto. ${ }^{19}$ Em vez de afirmar que há um modelo de referência sem objeto, porque ele pode ser visado sem existir, o que Husserl diz, se o estou a interpretar bem, é que uma vivência pode estar na consciência - o que só pode querer dizer que nem todas estão nela deste modo - sem que o objeto exista. É o caso do deus Júpiter que referi há pouco, exemplo que é dado pelo próprio Husserl um pouco mais adiante relativamente à passagem que estou a comentar. Ou seja, não me parece que se possa falar de um modelo de referência sem objeto, mas sim um modelo que tanto se pode aplicar aos casos em que a referência existe como não, ou seja, a casos em que o objeto é apenas presumido. Se não há lugar, como Husserl defende, ${ }^{20}$ para estabelecer uma distinção entre vivermos o objeto, por um lado, e, por outro, a vivência intencional que a ele se dirige, então, quando a vivência está presente, está consumada a relação intencional. Por isso, no modelo proposto, cabem, uma vez mais de acordo com os exemplos de Husserl, Júpiter, Bismarck, a Torre de Babel ou a Catedral de Colónia. ${ }^{21}$

Por fim, e este é um outro aspeto igualmente importante, a teoria a priori do direito de Reinach aproveita a distinção feita por Husserl, no $\S 14$ dos Prolegómenos, entre uma ciência teorética e uma ciência normativa. A primeira diz o que é e a segunda o que deve ser, independentemente de poder ser ou de nunca vir a ser. A primeira exprime-se num juízo do tipo «A é B»; a segunda numa frase desiderativa do tipo «A deve ser $B$ ». Há casos em que tais frases

18 Husserl, LU V, § 11, Hua XIX/1, pp. 385-386.

19 Ibid., p. 386.

20 Ibid.

21 Ibid., p. 387 . É claro que, de acordo com o representacionismo de Brentano, Bismarck e a Torre de Babel não poderiam caber no mesmo modelo. Resultou daqui a curiosa teoria de Meinong, segundo a qual objetos como a Torre de Babel teriam uma existência simplesmente mental. Bertrand Russell mostrou em tempos como uma tal teoria põe em causa o significado normal da palavra «existência», arriscando-se, por isso, a introduzir as maiores confusões em filosofia (cf. «On Denoting». In: Logic and Language, London / New York, Routledge, 1992, pp. 39-56, esp. p. 45). Este é, porém, um assunto que extravasa o âmbito deste ensaio. 
não se dirigem a ninguém, como no caso «um soldado deve ser corajoso» (com o pressuposto seguinte: «um soldado que não é corajoso não é um bom soldado»). Em relação a este ponto, Reinach afasta-se claramente do positivismo jurídico. Os princípios a priori do direito, para Reinach, não têm um carácter normativo, quer dizer, não dizem respeito a um dever-ser; pelo contrário, na sua qualidade de proposições teoréticas, exprimem relações de essência, das quais, obviamente - mas apenas posteriormente - podem resultar proposições normativas. ${ }^{22} \mathrm{O}$ papel das disposições jurídicas positivas, pelo contrário, é pôr estados de coisas de dever-ser para modificar estados de coisas de ser; e é também o de criar direitos e obrigações e, ao mesmo tempo, velar pela sua prevalência. Nos casos como os da promessa ou da ordem, que já referimos, elas garantem ainda a proteção jurídica de certas pretensões, ou o direito de reclamação em caso de ausência de satisfação. ${ }^{23}$

\section{Crítica do positivismo jurídico: a vinculação}

Há quem atribua à teoria pura do direito o objetivo de estabelecer as formas básicas, ou das categorias, da lei, no interior da esfera jurídica normativa. ${ }^{24}$ Mas Reinach segue, em minha opinião, um outro caminho, inspirando-se em afirmações de Husserl nas Investigações Lógicas. Trata-se, para ele, em primeiro lugar, de estabelecer relações de essência de carácter jurídico - relações que estabelecem uma vinculação entre um sujeito A e um sujeito B -, ou seja, de intuir ou tornar presentes essas relações mediante uma análise dos atos intencionais em que elas se dão. Vejamos um exemplo que Reinach nos dá na Introdução aos Grundlagen e que me parece desfazer este equívoco.

Se um indivíduo A pretende entrar na possa de alguma coisa que está na posse de outro indivíduo $\mathrm{B}$ e se $\mathrm{B}$ está disposto a renunciar de imediato a ela, a troca pode fazer-se de imediato. ${ }^{25}$ Porém, se a renúncia, da parte de $\mathrm{B}$, não puder ser feita de imediato (ou se só puder ser feita se forem cumpridas certas condições), surge a necessidade de um contrato; este estipulará em que condições A pode entrar na posse da referida coisa, bem como as condições que, uma vez satisfeitas, conduzem à necessária renúncia por parte de $\mathrm{B}$. Um contrato

22 Cf., sobre o positivismo jurídico e a importância das proposições normativas, Ana Paula Loureiro de Sousa, «Cossio, Kelsen e a Fenomenologia. Uma abordagem da experiência juridica». Phainomenon, 20/21 (2010): 213-225, p. 216.

23 SW, 254.

${ }^{24}$ Para a discussão deste assunto, com referência aos autores mais pertinentes, $c f$. Stanley L. Paulson, art. cit., p. 137.

$25 \mathrm{SW}, 142-143$. 
estabelece uma vinculação que, na opinião de Reinach, o direito positivo se recusa a admitir que pudesse existir antes de ele ser celebrado. Na perspetiva do direito positivo, nenhuma relação de vinculação entre $A$ e $B$ poderá existir antes de o direito a estabelecer. Da mesma forma, se pensarmos na relação de vinculaçãao entre quem promete e aquele a quem a promessa é dirigida, a pretensão a vê-la realizada, segundo a teoria a priori do direito, desaparece uma vez satisfeita; nada impede, porém, que o direito positivo prescreva que uma pretensão apenas desaparece quando a sua satisfação é confirmada por um tribunal. ${ }^{26}$ Por outras palavras, parece que, para cada relação a priori estabelecida pela teoria a priori do direito, será possível encontrar no direito positivo estipulações que a contradigam.

A tese que Reinach contrapõe é relativamente simples: sem a existência de uma vinculação a priori, qualquer vínculo de natureza jurídica permaneceria por fundamentar. A forma da vinculação apareceria como condicionada historicamente pelos conteúdos materiais que ela regula, podendo, inclusivamente, estar ausente em épocas históricas em que a matéria que enforma não tem existência. No caso da promessa, que é objeto de uma análise detalhada no $\S 2$ dos Grundlagen, a forma da vinculação é, inclusive, independente de um sentimento intencional evidente de que a promessa tem de ser cumprida. ${ }^{27}$ Para Reinach, a vinculação, que resulta do ato social de prometer, é um componente real da vivência da promessa e, por isso, desse ato decorre um outro ato de que resultará o seu cumprimento. Mas este último ato representa apenas o fechamento do círculo aberto pelo próprio ato de prometer; a priori, é apenas possível afirmar a necessidade desse ato, não que ele se venha efetivamente a realizar e que o círculo se feche. ${ }^{28}$ Por este motivo, a promessa, entendida como uma relação entre uma asserção que se inicia por «eu prometo que...»e um ato que a realiza, não perde o seu valor pelo facto de ter passado o tempo ou a ocasião estipulados para o seu cumprimento. É por este motivo, aliás, que faz algum sentido continuar a acusar alguém de uma promessa não cumprida. O sentimento de ter contraído um dever moral não é sequer relevante; obrigação jurídica e dever moral são coisas distintas e mesmo que se diga que alguém tem o dever moral de cumprir uma obrigação que contraiu, tal manifesta apenas uma relação de dependência entre uma obrigação e o dever moral. Devo, certamente, cumprir aquilo a que me obriguei, mas isso apenas prova que o dever se funda na obrigação, não que eles sejam a mesma coisa.

A vinculação, ao estabelecer uma relação entre uma obrigação e uma pretensão, exige o que Reinach chama um «portadon», ou um «suporte» (ein

26 SW, 239.

$27 \mathrm{SW}, 150$.

28 Stanley L. Paulsen, art. cit., p. 147. 
Träger); respetivamente, um sujeito $A$, portador de uma obrigação, que fica vinculado pela promessa que fez, e um sujeito $B$, portador da pretensão, que pode reivindicar o seu cumprimento. A referência a um portador é comum a todas as vivências e não apenas às configurações jurídicas, mas nem todos os sujeitos de vivências podem ser portadores de pretensões. É o caso dos animais, por exemplo. Portadores de pretensões são, diz Reinach, exclusivamente as pessoas..$^{29} \mathrm{O}$ facto de uma promessa ter sido feita cria, por si só, segundo Reinach, um estado de coisas que não existia anteriormente. Neste estado de coisas, verifica-se uma relação necessária entre o que foi prometido e a pretensão, por parte de quem recebeu a promessa, de exigir o seu cumprimento. ${ }^{30}$ Note-se que, se só quem recebeu a promessa está qualificado para formular a pretensão de que ela se cumpra, uma promessa não tem de se dirigir apenas a um único indivíduo; uma promessa pode dirigir-se a vários indivíduos em simultâneo sem que, por este facto, se tenham realizado vários atos sociais. Em qualquer caso, valerá sempre esta lei essencial: aquele ou aqueles a quem a promessa se não dirige não podem retirar dela qualquer pretensão. ${ }^{31}$

$\mathrm{Na}$ ocorrência, estamos na presença de um direito relativo, tal como podemos chamar relativo ao dever de cumprir uma promessa, ou ao de obedecer a uma ordem, no caso de ela ter emanado de alguém qualificado. «Relativo», porém, não é um adjetivo que desqualifique a natureza deste direito, mas sim, apenas, um traço do seu carácter específico, devido ao facto de instituir uma obrigação para com uma parte contrária (Gegnerschaft), contrariamente aos direitos absolutos, que instituem obrigações para consigo mesmo. Todavia, esta relação é de tipo diferente daquela que acontece entre dois fenómenos físicos, o que não impede Reinach de dizer que pertence à essência da promessa originar necessariamente uma pretensão de cumprimento. A comparação que estabelece tem de ser analisada com cuidado. A relação essencial que liga a promessa à pretensão do seu cumprimento é da mesma ordem que a que liga o número 3 ao número 2 na série dos números: ${ }^{32}$ por essência, 3 é
maior do que 2 .

$29 \mathrm{SW}, 151$.

${ }^{30}$ Uma questão interessante é a de saber se alguém se poderá ou não retratar após ter efetuado uma promessa. Reinach é de opinião que não. Uma ato de promessa é tão pouco suscetível de retratação quanto o próprio ato de retratação. Neste caso, o portador da obrigação e o portador da pretensão, ou seja, o destinatário da promessa, encontram-se em situações difepromessa cessa quando o beneficiário a ela renun renúncia que é imediatamente eficaz - a obrigação é destituído de qualquer eficácia.

${ }^{31} \mathrm{SW}, 172$.

$32 \mathrm{SW}, 155$. 
Poder-se-ia ainda perguntar o que é que separa a posição de Reinach do jusnaturalismo, para o qual parece existir uma idêntica docilidade da matéria perante uma forma jurídica intemporal e exterior à história. ${ }^{33}$ Reinach entende a noção de forma de um modo totalmente diverso, cuja origem de encontra na «doutrina do todo e das partes» na 3. Investigação Lógica de Husserl. Entre a promessa e a reivindicação de que ela seja cumprida existe a mesma relação ontológico-formal que Husserl detetara entre uma totalidade e os seus momentos dependentes, relação que é indiferente à matéria que constitui essa totalidade e às caraterísticas específicas de cada um dos seus momentos. A essência da promessa contém uma vinculação que obriga quem prometeu a cumpri-la - e, por conseguinte, a atender à reivindicação que ela o seja -, tal como existe uma vinculação entre a essência de uma superfície e a essência de uma cor.

É neste sentido que a doutrina de Reinach tem um carácter a priori. Suponhamos o caso de uma transferência de propriedade. Reinach não diz que se trata de um ato jurídico pelo facto de existirem certas normas que estipulam certos comportamentos que, uma vez cumpridos, permitem dizer que essa transferência tem valor jurídico. A norma jurídica consiste na descrição de certos comportamentos e na estipulação de que quem satisfizer as condições descritas está envolvido numa relação de carácter jurídico. ${ }^{34}$ A relação entre quem promete e aquele a quem a promessa é dirigida e a aceita é uma relação a priori desta natureza: o ato de prometer instaura uma reciprocidade entre duas pessoas, pelo menos, de tal forma que tem o mesmo significado dizer-se que alguém se obrigou a fazer determinada coisa $X$, ou que alguém tem o direito de reclamar dessa mesma pessoa, a ação X. Há aqui uma estrutura legal que tem um fundamento a priori e que, segundo Reinach, o direito positivo não cria, antes, pelo contrário, utiliza. ${ }^{35}$

\section{A teoria dos atos sociais de Reinach}

Um dos aspetos mais interessantes dos Grundlagen é o facto de Reinach defender que as configurações jurídicas são produzidas por atos sociais, ou seja, por um tipo de atos intencionais em que o Eu se revela ativo, ou dotado de espontaneidade. ${ }^{36}$ Por contraste, poder-se-ia dizer que quando o sentimento

${ }^{33}$ Sobre o sentido em que empregamos aqui os conceitos de matéria e de forma, $c f$. Gustav Radbruch, Rechtsphilosophie, trad. port. de Luís Cabral de Moncada, Filosofia do Direito. Coimbra: Arménio Amado Editor, 1937, 2.. ed., pp. 221 e ss.

${ }^{34}$ Cf. Stanley L. Paulson, art. cit., p. 143.

$35 \mathrm{SW}, 143$.

$36 \mathrm{SW}, 158$. 
de amor ou de ódio nos invade o Eu não é inteiramente ativo, embora tanto o amor como o ódio sejam dotados de uma intencionalidade particular. Note-se que nem todos os atos que desencadeiam efeitos públicos devem ser qualificados como atos socias. Uma decisão é um ato inteiramente privado, pode ser tomada sem ser sequer anunciada, e, no entanto, os seus efeitos podem não afetar apenas aquele que a tomou. ${ }^{37}$

Como todos os atos sociais públicos e não privados, a promessa implica o que Reinach chama uma Vernehmungsbedürftigkeit, uma necessidade de ser percebida. Recordemos aqui a definição de ato social nos Grundlagen: «Atos espontâneos que necessitam de ser percebidos [...].» ${ }^{38}$ Isto, provavelmente, significa que não apenas se dirigem a alguém, como, além disso, a intenção tem de ser reconhecida por aqueles a quem se dirigem. Há aqui um pequeno problema de tradução, cuja importância não se deverá talvez desprezar. Reinach não diz Wahrnehmungsbedürftigkeit, mas sim Vernehmungsbedürdftigkeit. À primeira vista, as diferenças entre os dois termos não parecem ser importantes, podendo ambos significar uma idêntica necessidade de ser percebido, pelo que as traduções francesa e italiana dos Grundlage, e eu seguia-as em relação a este assunto, optam por traduzir Vernhemung por «perceber». Todavia, quando reparamos que o substantivo alemão Vernehumung, no contexto da linguagem jurídica, pode ter o significado de «declaração solene», percebemos que há algo mais nas razões da sua escolha por Reinach.

(Entre parêntesis, chamo a atenção para o facto de existir uma ideia muito semelhante em Husserl no segundo volume das Ideias, embora Husserl não tenha a intenção de fundamentar a priori o direito. Husserl afirma ${ }^{39}$ no $\S 51$ que uma forma das pessoas agirem umas sobre as outras é interagirem num agir (Tun) espiritual, de tal forma que realizam atos com a intenção de serem entendidas por outras pessoas e, ao provocarem a captação compreensiva de tais atos por elas, determinam nelas, em resposta, certos modos de comportamento pessoal. Constatamos também aqui, por conseguinte, uma Vernehmungsbedürftigkeit.)

A contraprova da necessidade desta Vernehmungsbedürftigkeit estará no facto, que Reinach também refere, de que podemos renunciar factualmente a comunicar um ato de natureza social - por exemplo, dar uma ordem - quando sabemos que somos entendidos por outros meios, um olhar, por exemplo, ou um gesto. Mas aqui a renúncia é meramente factual e o gesto é uma espécie de palavra que não chegou a ser dita ou não pôde ser dita. Esta necessidade

\footnotetext{
$37 \mathrm{SW}, 158-159$.

$38 \mathrm{SW}, 159$.

39 Ideias II, § 51, Hua IV, 192.
} 
de serem percebidos radica na natureza dos atos sociais, mas também na nossa própria natureza, enquanto sujeitos que os realizam. De facto, para nós, o acesso à vida psíquica dos outros homens apenas se pode fazer, pelo menos nas situações normais, mediante o acesso às suas expressões fisicas. Assim, por exemplo, não diremos que dois atos percetivos, realizados por duas pessoas diferentes, dirigidos a um mesmo objeto, sejam atos sociais, nem mesmo quando os dois olhares se encontram e notam que estão a ver o mesmo. Uma simples convergência dos olhares não constitui por si só um ato social. ${ }^{40}$ A expressão verbal da promessa parece ser, assim, uma condição do carácter vinculante da promessa. ${ }^{41}$ Por outras palavras, quem promete não pode, sem contradição, agir em sentido contrário ao que se comprometeu fazer, na altura e nas circunstâncias previstas. (Como é óbvio, o agir, que fecha o círculo da promessa, tanto se pode seguir de imediato ao ato de prometer, como ser diferido até ao momento em que estão presentes as condições inicialmente estipuladas para que a promessa seja cumprida.) Compreendemos ainda o que significa esta necessidade de ser percebido se compararmos a promessa ou a ordem com as disposições jurídicas, a que Reinach chama Bestimmungen. O objetivo destas disposições é o de regular normativamente uma dada situação, pelo que instauram o efeito que pretendem simplesmente como consequência do facto de terem sido promulgadas; ao invés, no caso de uma promessa, promete-se a alguém, tal como, no caso de uma ordem de comando, se ordena a alguém.

Em todos os atos sociais, a execução e a sua manifestação têm um carácter voluntário ou espontâneo. ${ }^{42}$ Contudo, nem todos os atos voluntários ou espontâneos são obrigatoriamente sociais, mesmo quando se dirigem a terceiros. Mas também nem todos os atos que se dirigem a um outro necessitam de ser percebidos por ele; é o caso do perdão, diz Reinach. A pessoa a quem perdoo não necessita de saber que foi perdoada por mim para que o perdão seja efetivo. Neste caso, porém, não falaremos de um ato social. O que Reinach parece querer dizer é que a realização de um ato de perdão não envolve necessariamente a necessidade de proferir uma asserção do género «eu perdoo-te». Poderíamos ainda ver o caso particular da oração. Não há motivos para lhe negarmos o carácter de um ato social, pelo menos para aqueles que acreditam

40 Sobre este último assunto, cf. René Toulemont, L'Essence de la Société selon Husserl. Paris: PUF, 1962, p. 100.

41 De acordo com Armin Burkhardt, em «Verpflichtung und Verbindlichkeit. Etische Aspekte in der Rechtsphilosophie Adolf Reinachs», in: Kevin Mulligan (Ed.), ob. cit., pp. 155-174, p. 159, não haveria, em todos os Grundlagen, outra justificação para a Verbindlichkeit senão esta.

42 SW, 159. 
que Deus existe. E, todavia, faltam, ou podem faltar-lhe, aquelas caraterísticas da visibilidade que a atribuímos aos atos sociais: uma oração pode ser silenciosa, ou seja, não acompanhada por gestos, nem por um simples mover dos lábios. Simplesmente, a definição anterior de ato vale apenas para os atos realizados entre sujeitos humanos. Quando tal não acontece - ou seja, quando admitimos a possibilidade de uma comunicação que seja de ordem meramente espiritual - faltam aos atos aquelas caraterísticas que apenas valem para os casos em que as nossas vivências não podem ser captadas diretamente. ${ }^{43}$

Em certos atos sociais, a ação tem lugar inteiramente no interior do agente; é o caso, por exemplo, de uma tomada de decisão. Já o ato da promessa encontra-se sempre dirigido a outras pessoas. ${ }^{44} \mathrm{Na}$ medida em que um ato como a promessa implica o seu reconhecimento por parte de outro a quem algo é prometido, a linguagem surge como um dos elementos constituintes do ato social em causa. ${ }^{45} \mathrm{O}$ que obviamente significa que quando me dirijo a mim mesmo dizendo "prometo a mim mesmo que...» não estou, de facto, a prometer. Pela caraterística que foi apontada em último lugar, a promessa parece assemelhar-se ao comando. Registemos, porém, algumas diferenças significativas. Enquanto o comando implica uma ação resultante de quem recebe a ordem, a promessa implica uma ação resultante de quem a faz; enquanto uma ordem, para ser efetiva como ato social, implica, da parte de quem ordena, uma qualificação específica para o fazer e uma disponibilidade para aceitar ordem da parte daquele, ou daqueles, a quem ela se dirige, já no caso da promessa o simples facto de ela ter sido feita resulta uma obrigação e uma pretensão. ${ }^{46}$ Uma semelhança, contudo, parece ser possível estabelecer entre estes dois atos. Tal como o ato social inaugurado pelo ato de prometer só termina quando a promessa é efetivamente cumprida, também o ato de comandar só tem o seu termo quando a ordem é efetivamente executada. Para nos servirmos de uma imagem do próprio Reinach, diremos que, tanto a ordem, como a promessa, instauram um círculo, mas que ele se fecha de maneira diferente num e no outro caso. No caso da ordem, ele fecha-se quando ela é executada por aquele a quem se dirige, ao passo que no caso da promessa fecha-se quando aquele que prometeu cumpre a promessa feita. ${ }^{47}$

$43 \mathrm{SW}, 161$.

${ }^{44}$ Herbert Spiegelberg, The Phenomenological Movement. The Hague / Boston / London: Martinus Nijhoff, 1982, p. 197.

${ }^{45}$ Cf. Ronan de Calan, art. cit., p. 29.

${ }^{46} \mathrm{SW}, 172$.

47 De uma forma geral, podemos dizer que cada tipo de ato social abre um círculo que se fecha apenas quando tem lugar o comportamento específico que ele visa desencadear. Desta situação deverá distinguir-se uma outra, que tem com ela alguma relação, que acontece quando um ato social desencadeia, não um comportamento tendente a fechar o círculo aberto por ele, 


\section{Uma ontologia realista do direito}

Uma certa relação tem carácter jurídico quando podemos exigir dos outros uma conduta determinada, ou quando os outros no-la podem exigir. Mas, para que isso seja possível, considera-se, regra geral, que é necessária a existência de um conjunto de normas. Assim, por exemplo, se compro alguma coisa, o vendedor pode exigir-me um pagamento em dinheiro, mas se pedir a um amigo uma certa quantia emprestada não posso exigir que ele ma empreste. Ora, como nem todas as normas têm um carácter jurídico, parece que só o poderão adquirir quando existem uma autoridade que as impõe e tribunais que as fazem respeitar. ${ }^{48}$ É a tese do reducionismo normativo, segundo a qual uma proposição tem carácter jurídico quando pode ser transformada numa proposição normativa, servindo essa transformação de prova do efetivo carácter jurídico da primeira proposição. ${ }^{49}$ Assim, por exemplo, uma proposição que me obriga a pagar um empréstimo no prazo e nas condições estipuladas pode ser transformada na proposição - dirigida, desta vez, a uma autoridade policial ou judicial - que diz que quem não pagar um empréstimo nessas condições está sujeito a sofrer uma punição. A doutrina de Reinach parece semelhante a esta, tanto mais que os comportamentos que acabámos de descrever parecem poder subsumir-se na categoria geral das obrigações correlativas, de que nos fala o $\S 2$ dos Grundlage. $^{50} \mathrm{O}$ que dissemos sobre a sua teoria dos atos sociais permitir-nos-á ver que não é bem assim.

Regressemos à nossa análise da promessa. Quando o indivíduo A promete qualquer coisa ao indivíduo $B$, este tem o direito de exigir àquele que cumpra a promessa. Mas o seguimento da definição que apresentámos parece remeter esta exigência para o campo do direito positivo, uma vez que a norma que é usada deverá ser imposta por uma autoridade ( «os fatores que instituem o direito», como lhes chama Reinach, que critica esta tese ${ }^{51}$ ) e são os tribunais que a fazem respeitar. Não há aqui a possibilidade de estabelecer uma relação a priori. Cinjamos, todavia, mais de perto a dificuldade. É que o direito tem sempre um carácter impositivo e constrangedor que parece dificultar o estabelecimento de uma doutrina a priori. Seria assim difícil colocá-lo, como é a pretensão de Reinach, do lado da lógica, enquanto esta é - seguindo a tese de Husserl nos Prolegómenos - uma ciência teórica, onde se exprimem relações

mas sim um novo ato social de tipo diferente. É assim, por exemplo, no caso da pergunta, que é um ato social que desencadeia uma resposta. Sobre o assunto, $c f$. SW, 162.

${ }^{48}$ Cf. Angel Latorre, Introdução ao Direito. Coimbra: Almedina, 1978, pp. 15-18.

49 Stanley L. Paulson, art. cit., p. 140.

so $\mathrm{SW}, 149$.

51 Cf. SW, 142. 
entre essências, e não apenas uma ciência normativa. Reinach não exclui que a ciência jurídica seja composta por normas; simplesmente, defende que tais normas devem estar sujeitas a um princípio de avaliação que não é senão uma relação conceptual, ou seja, uma relação entre essências. O facto de certas disposições do direito positivo poderem contradizer as relações entre essências que caracterizam a doutrina a priori não significa que desmintam a validade desta, pois é somente esta que pode tornar aquelas disposições possíveis e compreensíveis.

Reinach defende ainda - contra o positivismo jurídico - que é tão absurdo pensar que as entidades jurídicas são criadas pelo direito positivo como seria absurdo pensar que os acontecimentos históricos são criados pela ciência histórica. Mas se é absurdo pensar que a ciência histórica instaura os acontecimentos históricos, não parece tão absurdo admitir pelo menos a hipótese de a ciência jurídica instaurar os conceitos jurídicos. Todavia, deixar-se-ia por explicar, a ser assim por que motivo a estrutura jurídica das normas fundamentais do direito pode ser idêntica em sistemas jurídicos positivos muito diferentes. ${ }^{52}$ Por conseguinte, do que Reinach está a falar, com a sua doutrina a priori, é da jurisdicidade de certos atos, ou que está envolvida em certos atos - por conseguinte, de entidades cuja existência é independente do facto de serem pensadas ou não - e não das disposições jurídicas normativas. Tal como é dito no início da Introdução aos Grundlage: se o positivismo jurídico estivesse certo, as proposições jurídicas normativas não seriam idênticas às proposições da aritmética, tais como $2 \times 2=4$, ou, em geral, às proposições das ciências; os fatores instituintes do direito teriam sido conduzidos a estabelecê-las em função de circunstâncias acidentais, tais como, por exemplo, as necessidades económicas de uma determinada época. ${ }^{53}$

\section{Crítica a David Hume}

A tese de Hume, que Reinach vai sujeitar a uma análise pormenorizada, ${ }^{54}$ é que a vontade não pode criar sentimentos; por conseguinte, a vontade de prometer não pode estar na origem do sentimento de me sentir obrigado por uma promessa. Como poderiam as simples palavras «eu prometo» estar na origem de um constrangimento, ou seja, de uma vontade obrigada? Para Hume, digo

52 Stanley L. Paulson, art. cit., p. 145.

${ }^{53} \mathrm{SW}, 141$. Referimos, mais atrás, o exemplo apresentado por Reinach: de acordo com uma proposição do direito alemão vigente, os créditos podem ser transferidos a terceiros pelo credor, sem prévio conhecimento por parte do devedor.

54 SW, 175-179. 
que contraio uma obrigação apenas porque o sentimento que acompanha a ideia de uma ação não realizada se tornou desagradável para mim: é a isso que se pode chamar sentir-se obrigado a realizá-la. Ora, tal como a vontade não gera sentimentos, também um sentimento não pode gerar outro sentimento: assim, o sentimento que me leva a prometer alguma coisa não pode, por si só, estar na origem de um segundo sentimento, que seria o de uma obrigação. ${ }^{55}$ Reinach argumenta, contra Hume, em três pontos:

1. Primeiro, começando por dizer que uma obrigação nasce quando há uma modificação nos acontecimentos do mundo, que faz existir uma coisa que cria essa obrigação. Deste ponto de vista, Hume só tem razão na medida em que defende que um sentimento não pode nascer de outro sentimento, mas que apenas um acontecimento pode estar na origem de outro sentimento. ${ }^{56}$

2. Segundo, dizendo que há, na realidade, com o ato de prometer, um acontecimento novo, uma modificação na existência objetiva do mundo. Se se quisesse afirmar que tal resultou apenas da vontade, seria um absurdo. A vontade é incapaz de, por si só, criar novos estados de coisas. Mas com o facto de eu ter prometido, quer dizer, com a promessa produziu-se qualquer coisa de novo, ou seja, um estado de coisas, de que uma obrigação decorre. ${ }^{57}$

3. Terceiro, acusando Hume de ver apenas o sentido do dever e não ver a relação a priori que a promessa estabelece entre quem promete e aquele a quem a promessa é feita. ${ }^{58}$ Por esta razão, Hume nem sequer fala da reivindicação de ver a promessa cumprida, que é levantada por aquele a quem algo foi prometido.

${ }^{55}$ Hume, Tratado da Natureza Humana, 3, II, V.

$56 \mathrm{SW}, 178$.

57 Servindo-nos da terminologia de John Austin, em How to do Things with Words, poderiamos dizer que $o$ ato de prometer tem um carácter performativo, ou seja, faz acontecer qualquer coisa, e que, além disso, tem um carácter perlocutório, pois desencadeia em quem o ouve uma reação, que, neste caso, consiste na expetativa de ver a promessa realizada, e legitima, da parte daquele a quem ela foi dirigida, a reivindicação do seu cumprimento. (A posição de Reinach, muito próxima da de Austin, afasta-se, neste ponto, decisivamente da de Aristóteles e é bastante superior a ela. Aristóteles também defendeu que uma promessa, ou um pedido, são substancialmente diferentes de uma asserção, mas não foi muito além do reconhecimento de que num caso ou no outro não nos encontramos perante proposições que tenham a forma do leguein ti kata tinos.)

${ }^{58} \mathrm{SW}, 179$. Sobre o a priori ontológico e não epistemológico em Reinach, $c f$. Herbert Spiegelberg, The Phenomenological Movement, p. 195. Uma relação pode ser dita a priori quando resulta de uma conexão entre essências e pode ser intuída enquanto tal independentemente da indução empírica. 
Neste sentido, poderíamos ainda acrescentar, a relação a priori em causa tem um carácter sintético, na medida em que se trata de uma conexão entre essências (a da promessa e a da reivindicação daquele a quem algo é prometido), na relação que mantêm umas com as outras. É uma relação entre ideias (no sentido humeano de relation of ideas), a qual não tem apenas o carácter analítico que Kant the atribuiu, interpretando parcialmente a posição de Hume sobre este assunto expressa no Inquiry. A crítica que Reinach dirige a Hume nos Grundlagen não nos deve fazer esquecer a sua valorização da problemática humeana da relation of ideas. Barry Smith mostrou-o em tempos num ensaio esclarecedor. Que tal relação não tenha apenas um carácter analítico, o único que Kant reteve, vê-se facilmente pelos exemplos que Hume fornece. Que as tonalidades do vermelho e do alaranjado são parecidas é uma relação entre ideias que tem carácter sintético, uma vez que o «ser parecido» não se encontra incluído - se quisermos conservar a terminologia kantiana - no conceito de nenhuma daquelas duas cores. A vinculação entre o ato de prometer e a exigência da promessa ser cumprida tem o mesmo carácter.

\section{A moralidade da promessa: a Verbindlichkeit revisitada}

Nos Grundlagen, criticando a teoria utilitarista de Wilhelm Schuppe, Reinach aborda ainda a questão da vinculação que resulta das promessas imorais. ${ }^{59} \mathrm{Se}$ eu prometo, por exemplo, matar alguém, deverei fazê-lo? Reinach não adopta uma solução que parece aqui possível, ou seja, negar que se trata de uma promessa. A argumentação contra esta dificuldade poderia ter a seguinte forma: não se deve confundir aquilo que é uma promessa com o facto de outra coisa diferente ser expressa com a linguagem da promessa. Assim, dir-se-ia que se trata de uma ameaça e que não tem o mesmo tipo de vinculação da promessa. Mas Reinach prefere seguir uma outra via. Diz que, do ponto de vista da natureza do ato em causa (ou seja, prometer), não há razão para distinguir entre uma promessa moral e uma promessa imoral. O que Reinach parece querer dizer é que entre a promessa e o seu cumprimento existe apenas uma relação externa baseada na essência de ambos, de modo que considerações de carácter moral não podem afetar essa relação.

É interessante verificar que se, por um lado, Reinach afasta a vinculação resultante do ato de prometer de qualquer intromissão de natureza moral, para considerar apenas a sua essência, por outro, Schuppe, negando a existência de uma vinculação no sentido que Reinach confere ao termo, introduz considerações de natureza moral na sua análise. O não cumprimento da promessa, 
segundo Schuppe, significaria, em primeiro lugar, um dano causado à legítima expectativa de terceiros, que o direito positivo deve acautelar, impedindo - nos casos em que quem prometeu não quer cumprir o que prometeu - os efeitos negativos de uma flutuação da vontade. (Schuppe não considera, como é óbvio, o caso em que de uma flutuação da vontade não resultam quaisquer efeitos negativos. ${ }^{60}$ ) Assim, deverei, pelo menos em certas circunstâncias, cumprir as promessas feitas para não cair sob a alçada da lei.

Ora, para Reinhold, é o fato de a relação entre a promessa e o seu cumprimento ser de carácter externo (e, por conseguinte, sintética) que permite que uma promessa possa ser julgada do ponto de vista moral. A ser assim, contudo, o que Reinach defende acerca da natureza da Verbindlichkeit talvez necessite de um complemento. Vimos atrás que esta parecia resultar do simples facto de A ter prometido a $\mathrm{B}$ realizar a ação X; a expressão pública de uma promessa compromete quem prometeu e ata a sua vontade de forma que o beneficiário da promessa tem o direito de reivindicar o seu cumprimento. Vemos agora uma outra ideia. A vinculação parece adquirir um carácter moral, no sentido em que se poderá dizer que é moralmente superior o cumprimento da promessa ao seu não cumprimento. Da mesma forma, o carácter eventualmente imoral de uma promessa justifica a intervenção do direito positivo; embora ele não possa interferir na relação essencial que também subsiste neste caso - ou seja, não podendo estar na origem do carácter a priori da vinculação, também não a pode dissolver -, pode, contudo, impedir o cumprimento de promessas das quais possa resultar, por exemplo, dolo para alguém. ${ }^{61}$ A distinção que há aqui a fazer é entre o plano jurídico e o plano moral, pois embora o segundo seja superior ao primeiro, é totalmente, não obstante, independente dele. Assim, uma frase como: «não tenho apenas o direito, mas também o dever», significa apenas que um mesmo comportamento pode ser relacionado com dois pontos de vista diferentes: por um lado - no caso do direito - estou diante de uma ação que me é permitida, por outro - no caso da moralidade -, diante de uma ação que me é exigida. ${ }^{62}$

60 SW, 185. A argumentação de Reinach tem o seguinte teor: o conceito de flutuação da vontade e o conceito de efeito negativo, ou dano, são completamente independentes, pelo que é possivel pensar uma coisa sem a outra. Além disso, de um dano considerável não nasce uma vinculação mais forte do que no caso de um dano ligeiro.

61 Sobre a possibilidade de intervenção do direito positivo, cf. Herbert Spiegelberg, ob. cit., p. 199.

${ }^{62} \mathrm{SW}, 190$. 


\begin{abstract}
In this paper I will focus on Adolf Reinach's work A Priori Foundations of Civil Law. Reinach, a member of the so-called "Circle of Göttingen", formed around Edmund Husserl, sought in this work to apply phenomenology, understood as a doctrine of essences, to the problem of the constitution of legal norms. Surprisingly, however, his starting point is an analysis of the promise - whose legal status is weak, appearing only in some civil codes (as the Portuguese), in expressions such as "promise of sale" - and the Verbindlichkeit it establishes between the one who makes the promise and the person who is promised something. Between promise and its fulfilment Reinach establishes a logical relation of cause and consequence, although he claims a different status for his legal formalism from that of Kant's. In this paper I will address not only Reinach's starting point, but also his claim to ground the Science of Law on objective legal formations, which can be intuited in the same way numbers or physical objects are intuited.
\end{abstract}

